\title{
Um estudo bioecológico das relações de amizade em sala de aula inclusiva
}

\section{A bioecological study of the relations of friendship in an inclusive classroom}

\author{
Rosana Assef Faciola* \\ Universidade Federal do Pará - UFPA, Belém, Pará, Brasil \\ Fernando Augusto Ramos Pontes** \\ Universidade Federal do Pará - UFPA, Belém, Pará, Brasil
}

Simone Souza da Costa Silva***

Universidade Federal do Pará - UFPA, Belém, Pará, Brasil

\begin{abstract}
RESUMO
Este artigo apresenta os resultados de uma pesquisa, a qual investigou as interações entre uma aluna com deficiência visual e seus colegas, em uma sala de aula inclusiva, de uma escola pública de Belém do Pará, com o objetivo de averiguar como se estabelecem as relações de amizade neste contexto de desenvolvimento. Para a coleta de dados foram utilizadas duas técnicas: a observação e a entrevista sociométrica com o sujeito focal e seus colegas de classe. Os dados obtidos mostraram que as respostas da aluna quanto as suas preferências de amizade estão relacionadas à cooperação e ao compartilhamento em sala de aula e na área de recreação. O mesmo não aconteceu com os outros alunos, cujos dados obtidos na entrevista e observação, apontaram diferenças relevantes quanto às preferências de amizade, sobretudo no que se refere à aluna com deficiência.
\end{abstract}

Palavras-chave: educação inclusiva, relações de amizade, desenvolvimento infantil, inserção ecológica.

\begin{abstract}
This article presents the results of a research that investigated the interactions between a student with a visual impairment and her colleagues in an inclusive classroom, of a public school in Belém of Pará, with the purpose to know how these relations of friendship are established in this context of development. For data collection, were used two techniques: the observation and the sociometric interview with the focal subject and her classmates. The data collected showed that the responses of the student regarding to her preferences of friendship are related to cooperation and sharing in the classroom and in the school playground. The same didn't happen with the other students, whose data obtained in the interview and observation pointed relevant differences concerning to friendship preferences, with particular regard to the student with disability.
\end{abstract}

Keywords: Inclusive education, relations of friendship, child development, ecological insertion. 


\section{I ntrodução}

A literatura concernente ao tema amizade aqui tratado, reconhece a importância das relações sociais no estabelecimento das mudanças que se processam ao longo do tempo na vida dos indivíduos. Assim, considerando-se que 0 desenvolvimento infantil acontece primeiramente na família, na qual existe uma organização complexa de relações de parentesco, e também uma história individual que constrói padrões específicos de condutas, relações, emoções e práticas educacionais. Os estudos sobre relacionamento valorizaram, durante décadas, as relações entre adultos-crianças. Partindo-se desse princípio, e sustentados nesta visão adultocêntrica, as pesquisas nesta área focaram sua atenção sobre o vinculo mãe-bebê. Nos últimos anos, contudo, têm se destacado a importância dos relacionamentos entre pares como um contexto gerador de mudanças fundamentais para o indivíduo (HINDE, 1997; HARRIS, 1995). O argumento dos pesquisadores apresenta como idéia central, a noção de que os parceiros de relação em estágios próximos de desenvolvimento conseguem ser mais coerentes na interação com seu coetâneo, na medida em que são mais capazes de se colocar no lugar do outro do que o adulto.

A escola, por exemplo, é um contexto privilegiado para o estabelecimento de relações criança-criança, pois na sociedade moderna as crianças passam uma grande parte do tempo dentro do ambiente escolar, convivendo com crianças de sua idade. A escola, portanto, constitui um ambiente diferenciado, não apenas por cumprir sua função educativa formal aos conceitos científicos, mas, também, por ser um espaço rico de socialização para as crianças.

Para Corsaro (1985) a socialização consiste na participação das crianças e a produção de uma série de culturas de pares, nas quais o conhecimento e as habilidades da criança são gradualmente transformadas em conhecimento e habilidades necessárias para a participação no mundo adulto.

No contexto da Escola Inclusiva, por sua vez, a proposta de inclusão de crianças e jovens com deficiências cria oportunidades para a interação dos alunos com e sem deficiências, o que se constitui em uma forma de diminuir o preconceito e discriminação sofridos pelos deficientes. Vários estudos (STAINBACK; STAINBACK, 1999; FERREIRA; GUIMARÃES, 2003; MITTLER, 2003; FÁVERO; PANTOJ A; MANTOAN, 2004; BEYER, 2007; DORZIAT, 2007; CARVALHO, 2008; MACHADO, 2009) têm enfatizado que a inclusão garante o acesso e a participação de todos, respeitando-se, acima de tudo, a diversidade dos educandos.

Mittler (2003), em seu estudo sobre a inclusão, afirma que a escola inclusiva foi planejada para beneficiar todos os alunos, incluindo os com deficiências ou com dificuldades de aprendizagem. No entanto, a 
realidade brasileira de implantação da política inclusiva, que coloca alunos com deficiências em turmas regulares de ensino tem gerado muitos conflitos (OLIVEIRA, 2007), em função de um histórico marcado por práticas excludentes e que impossibilitavam o convívio das pessoas com e sem deficiências em qualquer ambiente, dentre eles, o escolar.

Oliveira (2007) ressalta que a inclusão escolar dos alunos com deficiências tornou-se um problema para a escola, pois de invisível, eles passaram a ser visíveis, de não-problema passaram a ser problema, evidenciando a passagem de um estado de negação a um estado de problematização.

Diante dessa realidade, uma considerável soma de estudos (BISHOP; JUBALA; STAINBACK; STAINBACK, 1999; STRULLY; STRULLY, 1999; GARCIA, 2005) sobre as relações de amizade entre crianças com e sem deficiências demonstram que, apesar das controvérsias em torno do projeto inclusivista, as oportunidades de interação entre essas crianças aumentaram com a proposta de inclusão escolar. Entretanto, para Bishop; Jubala; Stainback e Stainback (1999), embora as interações entre deficientes e seus pares ditos normais tenha aumentado com a inclusão, estas raramente se transformam em amizade.

As pesquisas sobre relações de amizades desenvolvidas por Garcia (2005) demonstram que cada deficiência afeta a amizade de modo particular, mas, geralmente, não impedem o seu desenvolvimento. Além disso, o autor afirma que no ambiente escolar há uma ênfase no papel da amizade para a adaptação do aluno, pois as amizades entre pares têm papel fundamental no desenvolvimento, principalmente em se tratando de crianças com deficiências que necessitam de maior ajuda e apoio.

Strully e Strully (1999, p. 170) referindo-se ao valor da amizade, afirmam que: "desenvolver amizades significa viver e aprender junto. Significa intencionalidade, participação na comunidade e inclusão". Os autores enfatizam, também, a necessidade de se construir e estimular amizades na escola que precisa saber que, sem amigos, não se aprende eficientemente.

Assim, partindo-se do pressuposto de que a escola é considerada o lugar ideal para o surgimento de amizades (BISHOP; JUBALA; STAINBACK; STAINBACK, 1999; STRULLY; STRULLY, 1999; GARCIA, 2005), surge então questionamentos em relação a como se dá o convívio entre os alunos com e sem deficiências, ou seja, como ocorrem as interações e relações de amizade entre os mesmos no ambiente escolar inclusivo.

As idéias de Bronfenbrenner (1996; 1999), representante de uma visão ecológica e sistêmica do desenvolvimento humano, contribuem para este tipo de estudo através de seu modelo teórico, que propõe uma investigação das interações entre o sujeito e o contexto em que 
vive, formadas pelo lugar, pessoa, tempo, atividades, papéis e instituições. Nesse sentido, o processo do desenvolvimento humano está apoiado essencialmente em quatro níveis dinâmicos e interrelacionados, configurando o que se conhece como modelo PPCT (PROCESSO-PESSOA-CONTEXTO-TEMPO). Todos esses sistemas ocorrem simultaneamente, durante o ciclo de vida, através de interações recíprocas entre pessoa e meio ambientes (biológico, psicológico, social).

O Processo enfatiza os processos proximais, que são as formas particulares de interação entre a Pessoa e o Contexto que acontecem ao longo do Tempo. O contexto é definido como um sistema estruturado em quatro instâncias, que se articulam e se influenciam: os microssistemas definidos como padrões de atividades, papéis e relações interpessoais experienciadas em ambientes singulares, onde as pessoas interagem uma com as outras; os mesossistemas, identificados como sistemas onde ocorrem acontecimentos em diferentes lugares, envolvendo relações entre diferentes locais de desenvolvimento; os exossistemas, concebidos como estruturas sociais mais amplas que incluem os micro e mesossistemas e que influenciam as características dos sistemas e dos indivíduos em níveis mais simples; e os macrossistemas, vistos como as estruturas sociais mais amplas, em termos de valores, normas e sistemas políticos.

Considerando-se a escola como contexto de desenvolvimento, e, por conseguinte, a sala de aula e a área do recreio como microssistemas, uma vez que nesses espaços ocorrem processos proximais, através do estabelecimento de relações e interações interpessoais das crianças ao longo do ano letivo, este estudo objetivou analisar de que maneira se estabelecem as relações de amizade entre uma aluna com deficiência visual e seus pares neste contexto de desenvolvimento. Nesta perspectiva, justifica- se a opção pela teoria proposta por Urie Bronfenbrenner (1999) como suporte teórico, para a realização desta pesquisa, pelo potencial que a teoria tem para explicar a importância do contexto para o estudo da pessoa em desenvolvimento.

Além disso, a proposta Bioecológica de investigação através da observação naturalística privilegia a inserção ecológica (CECCONELLO; KOLLER, 2003) dos pesquisadores no ambiente a ser estudado, resgatando as capacidades e competências da pessoa em desenvolvimento. A metodologia da inserção ecológica proposta pelas autoras é baseada no modelo Bioecológico do Desenvolvimento Humano proposto por Bronfenbrenner (1999) e envolve a sistematização dos quatro níveis dinâmicos e inter-relacionados (PPCT).

O processo proximal ocorre através da interação do pesquisador, participantes, objetos e símbolos presentes no contexto da pesquisa e devendo ser focalizado através da observação naturalística, 
entrevistas estruturadas e conversas informais que possam ocorrer no período da inserção ecológica do pesquisador. A pessoa envolve a presença física do pesquisador no ambiente da pesquisa, o qual deve ser percebido e analisado a partir da percepção do pesquisador e dos participantes do estudo, valorizando-se a experiência individual de cada pessoa dentro do contexto. O contexto deve ser analisado através da participação do pesquisador no ambiente da pesquisa e a partir dos relatos de cada participante da pesquisa. O tempo envolve o acompanhamento dos participantes da pesquisa por um determinado período, seja no nível do micro, do meso ou do macrotempo (CECCONELLO; KOLLER, 2003).

A inserção ecológica, proposta por Cecconello e Koller (2003), é ideal para estudar o fenômeno do desenvolvimento no contexto, para garantir a validade ecológica da pesquisa em seu ambiente natural porque, para as autoras, a inserção propicia a valorização da influência das características das pessoas investigadas, do contexto no qual estão inseridas, do tempo em que estão vivendo e dos processos proximais ocorridos entre elas, e também entre elas e 0 investigador.

Para alcançar os objetivos deste estudo, foi proposta a inserção ecológica da pesquisadora em uma sala de aula inclusiva, a fim de verificar como, de fato, se estabelecem as relações de amizade entre os alunos com e sem deficiências.

\section{Método}

A investigação desenvolvida nesta pesquisa utilizou uma abordagem qualitativa, através de um estudo de caso, realizado a partir da inserção ecológica da pesquisadora nos microssistemas (sala de aula e área do recreio) para observação das interações existentes entre uma criança com deficiência visual e seus pares.

A pesquisa qualitativa envolve a coleta de dados descritivos, obtidos no contato direto do pesquisador com o objeto estudado, enfatizando-se mais o processo do que o produto, preocupando-se em retratar as perspectivas dos participantes (BODGAN; BIKLEN, 1994). Além disso, num estudo qualitativo, o estudo de caso constitui uma expressão importante na pesquisa educacional (TRIVINÕS, 1987).

O método de estudo de caso é apropriado para realização de pesquisas no contexto de desenvolvimento. De acordo com Yin (2005), o estudo de caso é utilizado para investigar fenômenos sociais complexos, dentro de um contexto de vida real, especialmente quando os limites entre o fenômeno e o contexto não estão claros e quando o contexto tem uma influência forte sobre o fenômeno a ser investigado. 


\section{Contexto de realização da pesquisa}

O ambiente de pesquisa foi uma turma inclusiva de uma escola da Rede Regular de Ensino Público da cidade de Belém do Pará, considerada como local adequado e representativo para a pesquisa, em razão de sua destinação oficial para este tipo de serviço educacional. O diagnóstico dos alunos com deficiências nesta escola é feito pela Coordenação de Educação Especial (COEES).

É uma turma de $1^{a}$ série do ensino fundamental, composta por 25 alunos, dos quais três possuem deficiências, sendo um com deficiência visual e dois com deficiência mental. Nessa sala de aula as mesinhas são arrumadas de duas em duas em três fileiras. Dois dos alunos com deficiências sentam nas primeiras carteiras de filas diferentes; seus pares são crianças normais. O terceiro aluno com deficiência senta sozinho, na última carteira da fila do meio.

\section{Participantes}

Fizeram parte deste estudo os 25 alunos da classe, sendo 17 meninos e 08 meninas, incluindo a aluna com deficiência visual.

Dos três alunos com deficiência, foi escolhida como sujeito focal a aluna com deficiência visual, com 13 anos de idade, que frequentava regularmente a escola, ao contrário dos outros dois alunos que faltavam constantemente. Com o objetivo de preservar a identidade do sujeito focal desta pesquisa, será utilizado o nome fictício de Luana.

\section{Instrumentos e técnicas}

Os principais instrumentos utilizados nesta pesquisa foram: entrevista sociométrica e observação do comportamento interativo do sujeito focal e seus colegas em sala de aula e área do recreio.

A entrevista sociométrica consiste em uma técnica quantitativa que tem por objetivo conhecer as relações das crianças com seus colegas de classe. De acordo com Moreno (1962), em um teste sociométrico pede-se ao sujeito que escolha as pessoas que ele deseja ter como amigos no grupo do qual faz parte, ou ao qual poderia pertencer.

Para realização da entrevista sociométrica foi utilizado um questionário contendo cinco perguntas específicas ao problema da pesquisa, sendo todas relacionadas a eventos sociais que envolviam relações de amizade, e fichas individuais contendo o nome de cada um dos alunos da sala. Além da utilização de papel e caneta para as anotações feitas durante a entrevista e observações em sala de aula e área do recreio. 


\section{Procedimentos}

Inicialmente, foi feito um contato com a coordenadora do COEES para a apresentação do projeto de pesquisa e escolha da escola onde se realizaria o estudo. Após apreciação do projeto, a coordenadora indicou uma escola da Rede Estadual de Ensino Regular que é considerada referência em Educação Inclusiva na cidade de Belém, por ser uma das únicas escolas públicas da capital paraense que dispõe de profissionais da área da Psicologia e da Pedagogia, vinculadas ao COEES, para acompanhamento e apoio aos alunos com deficiências.

Em seguida, foi realizado contato com a direção da escola através de visita inicial para apresentar a proposta da pesquisa e entregar o Ofício de Autorização para que fosse assinado, manifestando concordância por parte da Instituição.

O Diretor da Instituição de ensino concordou com a pesquisa, encaminhando imediatamente a pesquisadora para a pedagoga da Escola, a fim de escolher a turma e os alunos.

Para a realização da pesquisa, a pedagoga da escola sugeriu as turmas de primeira série, pois todas as três turmas tinham alunos com deficiências. O critério para seleção de uma das turmas foi a receptividade e a disponibilidade da Professora e dos alunos.

Após a escolha e contato preliminar com a professora e os alunos, a pesquisa foi configurada para ser feita em duas etapas, com a aplicação de duas técnicas metodológicas diferentes: a primeira foi a observação comportamental; e a segunda foi a entrevista sociométrica.

Para tanto, foi feita uma análise da relação entre comportamento interativo e escolha sociométrica do sujeito focal e de seus colegas de classe, a fim de mostrar se havia preferências por parceiros na medida de observação e na medida sociométrica, a que essas preferências estão relacionadas e quais os comportamentos mais evidentes que levaram a essa escolha.

Através dos resultados, objetivou-se considerar as amizades recíprocas (quando há reciprocidade na preferência positiva por parceiros); amizades unilaterais (quando a criança cita outra como preferência positiva, mas não foi escolhida pela mesma); e mutualidades negativas (quando há reciprocidade na preferência negativa por parceiros).

\section{Adaptação da Técnica}

Para a obtenção dos dados junto à aluna, inicialmente pretendia-se aplicar um teste sociométrico usando fotografias dos colegas para que ela pudesse escolher três alunos que julgasse serem seus amigos 
e três que não considerasse seus amigos. No entanto, em razão de sua deficiência visual, os procedimentos metodológicos necessitaram de adaptação.

Assim, decidiu-se escrever o nome de todos os alunos da classe em fichas de papel para que a aluna tirasse o nome dos colegas individualmente, para então classificá-lo como amigo ou não. Vale ressaltar que, por ter uma visão subnormal, a aluna, com grande esforço visual, consegue ler algo que esteja bem próximo ao seu olho direito.

\section{Etapas da Pesquisa}

Na primeira etapa, iniciou-se o período de inserção ecológica da pesquisadora no microssistema sala de aula e área do recreio, três vezes por semana, para observações no turno matutino, por aproximadamente duas horas, durante dois meses. Além de tornar a presença da pesquisadora mais familiar, essas observações permitiram à mesma conhecer a rotina de sala de aula, bem como identificar todos os alunos da sala pelos seus respectivos nomes.

Ao término de dois meses, foi iniciada a coleta de dados, propriamente dita.

Inicialmente foram realizadas observações em sala de aula e área do recreio, a fim de verificar o comportamento da aluna e sua possível interação com seus pares. Nesta segunda etapa, quase ao final dos dois meses, foi aplicada a entrevista sociométrica com a aluna com deficiência visual.

Antes de iniciar a entrevista sociométrica, foi explicada ao sujeito focal a diferença entre o que seria um amigo e um colega, ressaltando, de modo bem simples, que amigo é aquele no qual podemos confiar nossos segredos, contando nossas alegrias ou problemas, que sabem nos ouvir e nos dão apoio, ao passo que os colegas nós conhecemos, conversamos, mas não confiamos nossos segredos, alegrias ou problemas. Feito isso, deu-se início à entrevista na qual ela deveria ir tirando o nome de cada um dos colegas que estavam escritos em fichas individuais, para então classificá-los como amigos ou não, dizendo o porquê de suas escolhas. Esta entrevista foi realizada individualmente, em sala reservada no próprio espaço escolar.

Na realização da entrevista sociométrica com o sujeito focal, foram feitas cinco perguntas para verificar quais as preferências verbais positivas e negativas por parceiros. Inicialmente, a cada escolha, o sujeito lia o nome do colega e respondia as seguintes perguntas: 1) Ele(a) é seu amigo? Por quê? 2) Você gosta de sentar com ele(a)? Por quê? 3) Você brinca com ele(a) no recreio? 
Depois de falar de todos os alunos, foram feitas outras duas perguntas com o objetivo de confirmar as preferências verbais do sujeito focal. As perguntas foram as seguintes: 4) Quem você convidaria para sua festa de aniversário? Por quê? e 5) Quem você não convidaria para sua festa de aniversário? Por quê? Nessas duas perguntas foi solicitado à aluna que fizesse somente três escolhas.

A realização da entrevista sociométrica com os outros alunos da sala foi feita individualmente, seguindo os mesmos passos adotados com o sujeito focal em dia previamente combinado com a professora.

\section{Resultados e revelações do estudo}

A sistematização dos dados coletados, através das entrevistas e observações em sala de aula e área do recreio, resultou em um relato com a descrição das observações em torno da aluna com deficiência visual, no contexto da sala de aula, e análise das entrevistas, como demonstrado a seguir:

\subsection{Relato das observações}

Após um período de aproximadamente quatro meses de observações em sala de aula, foi possível verificar que diferentemente dos outros alunos, Luana senta sempre na primeira carteira em frente da mesa da Professora, que constantemente dá assistência a aluna, perguntando, regularmente, sobre a atividade que ela está fazendo, o que parece motivá-la a continuar suas atividades.

Luana permanece sempre com a cabeça bem baixa, perto do caderno apertando o olho direito, pois o seu foco visual se dá de forma lateral. Não se sabe o percentual de visão que esta aluna tem, pois o diagnóstico detalhado da deficiência de Luana feito pelo COEES não está na escola, porém, é possível constatar que ela possui baixa visão e que consegue enxergar, somente com um dos olhos, algo que esteja realmente bem próximo.

Na maioria do tempo de aula, Luana parece estar alheia ao que está acontecendo em sala de aula, participando muito pouco, pois não enxerga nada que esteja no quadro e suas atividades são diferenciadas. Freqüentemente, ela começa a falar sozinha e sempre que isso acontece a professora intervém, perguntando se ela está fazendo sua atividade. Diante da intervenção da professora, ela silencia e retoma a atividade. Se a professora demorar a fazer contato com a aluna, ela volta a falar sozinha, pois a colega que está ao seu lado está envolvida na atividade desenvolvida ou sendo explicada pela Professora.

Isto revela o papel fundamental ocupado pela Professora, a qual parece ser a principal responsável pela harmonia existente na sala, 
pois se comporta de maneira bem natural diante de seus alunos com deficiências, facilitando a interação dos mesmos com os outros alunos, não apenas através da arrumação da sala, juntando as carteiras de duas em duas para que as crianças sentem sempre em duplas, mas, também, promovendo atividades integradas, como por exemplo: leitura de histórias, durante as quais as crianças sentavam no chão em círculo; peças teatrais, com ensaios em sala de aula, nos quais havia participação de todos os alunos; entre outras atividades que possibilitavam maior interação entre os mesmos.

Do mesmo modo, em todas as atividades de grupos, a Professora está sempre incluindo os alunos com deficiências para participarem junto com os outros. Este posicionamento da Professora condiz com as considerações de alguns autores (KREBS, 2006; BISHOP; JUBALA; STAINBACK; STAINBACK, 1999) que consideram fundamental a postura do Professor como um gerador de oportunidades de interações que permitirão o desenvolvimento de relações de amizades.

Para Krebs (2006), a mediação do Professor é importante para identificar no aluno com deficiência algum atributo pessoal positivo para que os demais alunos não o rejeitem, no sentido de assegurar entre eles a reciprocidade, equilíbrio de poder e afetividade.

O desenvolvimento de amizades requer oportunidades de interação e o Professor deve criar situações nas quais os alunos com deficiências possam participar de maneira que suas limitações não se evidenciem, uma vez que, a condição básica que permite a um aluno com deficiência ter a oportunidade de desenvolver amizades com colegas ditos normais é o estar na presença desses colegas (BISHOP; JUBALA; STAINBACK; STAINBACK, 1999), em constante processo de interação.

\subsection{Análise das entrevistas}

Durante a entrevista sociométrica, na qual situações que envolviam relações de amizade, tipo: "Ele (a) é seu amigo(a)?" ou "Você gosta de sentar com ele(a)? ou você gosta de brincar com ele(a)?". Luana falou a respeito de cada um de seus colegas de classe. Foram consideradas amigas apenas as meninas. Ao ser perguntado se ela gostava de sentar com elas e o porquê, Luana declarou: "eu gosto de sentar com elas, porque elas prestam atenção na aula e me ajudam a fazer meus trabalhinhos". Luana também disse que brincava com todas as meninas na hora do recreio e que as amigas conversavam com ela na hora do lanche e ajudavam-na a descer e subir as escadas.

As respostas de Luana corroboram os resultados das pesquisas sobre amizade feitas por Garcia (2005) que afirma que a amizade com 
pares constitui uma importante fonte de apoio social que ajuda no enfrentamento às dificuldades sociais.

Nenhum menino foi classificado como amigo. Ao se referir aos meninos, considerou-os apenas colegas, pois não podia sentar e nem brincar com os meninos porque sua mãe não deixava. Entretanto, ao se referir a um dos colegas, que segundo ela, uma vez a ajudou a descer as escadas, disse: "Ele não conversa comigo. Às vezes penso: Poxa, nenhum coleguinha conversa comigo. Acho que eles não gostam de mim".

Durante a entrevista, ao serem feitas as perguntas sobre quais os três amigos que ela convidaria para sua festa de aniversário, Luana escolheu três colegas que mais frequentemente sentam com ela em sala de aula, e que, segundo ela: "são as minhas amigas que prestam atenção na aula, que me ajudam a fazer meus trabalhinhos e ficam conversando comigo na hora do recreio".

E quem ela não convidaria para sua festa de aniversário, foram três meninos que segundo ela "são enjoadinhos e gritam muito", e entre eles estava um dos alunos também com deficiência, o qual ela acrescentou: "ele só quer paquerar na hora do estudo". Esta resposta está, provavelmente, relacionada às orientações da família, da mãe em especial, que de acordo com resposta anterior de Luana, recomenda que ela não sente ao lado de meninos e não brinque com meninos na hora do recreio.

Em termos gerais, observa-se que a segregação sexual encontrada em grupos de crianças e pré-adolescentes onde não se encontram pessoas com atrasos em seu desenvolvimento caracteriza também os relacionamentos estabelecidos com pessoas como Luana. A literatura indica que a atração entre crianças do mesmo sexo é maior do que entre sexos diferentes (GARClA, 2006). Este fato parece estar associado aos tipos de atividades desenvolvidas em conjunto e aos estilos de interação. Enquanto as meninas estabelecem relacionamentos de compartilhamento em pequenos grupos onde conversam e apóiam-se mutuamente, os meninos preferem grupos maiores e atividades associadas a jogos e competição (DANIELSBEIRNESS, 1989; GRAHAM; COHEN; ZBIKOWSKI; SECRIST, 1998).

As informações coletadas na entrevista sociométrica com as outras crianças revelaram amizades recíprocas, pois todas as meninas da sala classificaram Luana como amiga, no entanto, nenhuma menina mencionou gostar de sentar ou brincar com ela na hora do recreio. $E$, apenas uma menina disse que convidaria Luana para sua festa de aniversário. Ao ser questionado o porquê, ela respondeu: "porque eu gosto muito dela".

A entrevista com os meninos apontou para amizades unilaterais, pois quinze meninos classificaram Luana como amiga e não como colega, como ela tinha classificado a todos eles. No entanto, nenhum deles disse gostar de sentar ou brincar com ela, ou que a convidariam para 
sua festa de aniversário. Apenas dois meninos não classificaram Luana como amiga, e sim como colega, revelando a mutualidade negativa entre os pares. Esses resultados revelam que as diferenças comportamentais e físicas de crianças e jovens com deficiências dificultam a inclusão no grupo e acentuam a desigualdade entre eles (BATISTA; ENUMO, 2004).

Durante as observações em sala de aula e área de recreação, constatou-se que as meninas são as únicas que ficam perto de Luana na sala de aula e, eventualmente, na hora do recreio. Não foram observadas interações com os meninos nem em sala de aula, nem no espaço de recreação.

\section{Considerações Finais}

Ao considerarmos as atividades desenvolvidas e, sobretudo, as relações interpessoais que ocorreram no período desta pesquisa, com especial atenção para a aluna com deficiência visual e seus pares, observamos que os procedimentos utilizados demonstraram, neste estudo de caso, que as relações de amizade ocorreram através de interações dentro e fora da sala de aula, a exemplo do espaço comum de recreação.

Tais interações estão relacionadas às colaborações prestadas pelas colegas e recebidas por Luana, durante as atividades feitas em sala de aula, assim como às brincadeiras e conversas nos horários do lanche.

Constatamos, então, que a vivência escolar da aluna com deficiência visual revela uma dificuldade de realizar tarefas de sala de aula, sem o apoio das colegas. Além disso, percebemos a mesma dificuldade na realização de outras atividades nos ambientes externos à sala de aula, como o descer e subir as escadas, caminhar para a área de recreação etc.

Percebemos que esta dificuldade de locomoção, por parte da aluna deficiente visual, se dá em decorrência das barreiras arquitetônicas existentes no ambiente escolar.

Apesar de a instituição ser referência em Educação Inclusiva, a Escola não realizou nenhum Projeto de Acessibilidade, a fim de incentivar e promover a independência dos alunos com deficiências, da maneira que prevê a Lei Federal $\mathrm{n}^{\circ}{ }^{\circ} 10.098$ de 19 de dezembro de 2000 , que dispõe sobre $o$ atendimento e a acessibilidade das pessoas com deficiência ou com mobilidade reduzida.

Observamos que o prédio escolar possui dois andares com uma escada e duas rampas de acesso ao segundo piso. A escada é extremamente perigosa em decorrência dos degraus estreitos, e com corrimão instalado apenas na metade do percurso. As rampas de acesso também não oferecem nenhuma proteção, pois não possuem 
corrimão e estão com o piso muito danificado, com ausência de algumas lajotas em toda sua extensão, tornando-se inacessível para uma aluna com deficiência visual, por exemplo.

Os resultados provenientes da entrevista sociométrica reforçaram os dados da observação comportamental, no que se refere às interações no auxílio durante a realização das tarefas de sala e brincadeiras na hora do lanche. Além desses dados, foi relatada a preferência pelas meninas que auxiliavam Luana no deslocamento da sala de aula para a área do recreio e vice-versa. Não foram observadas interações com meninos nem em sala de aula, e nem no recreio. Na entrevista constatou-se que a preferência negativa por meninos é resultante de orientação familiar, mais especificamente da mãe, que instruiu Luana a não sentar e nem brincar com meninos. Este dado remete-nos às influências do mesossistema família, no microssistema escolar, as quais devem ser consideradas para que se possam compreender determinados comportamentos dos alunos dentro da escola.

Os dados coletados corroboram as idéias de Garcia (2005) que ressalta que as respostas aos questionamentos feitos com relação à preferência confirmam que o comportamento pró-social (incluindo o cooperar e o compartilhar) têm sido um dos aspectos mais claramente associados à amizade. Na medida da observação e entrevista sociométrica, foi possível constatar que todas as preferências positivas de Luana sinalizam que suas amigas são aquelas que a ajudam na realização das tarefas escolares, que brincam e conversam com ela na hora do recreio e a ajudam a se locomover da sala para a área do recreio e vice-versa, incluindo o descer e subir as escadas.

A entrevista com os alunos sem deficiências demonstraram que a aluna com deficiência foi apontada como amiga por todas as meninas e pela maioria dos meninos. Entretanto, nenhum desses alunos mencionou gostar de brincar ou conversar com Luana na hora do lanche e somente uma aluna a convidaria para sua festa de aniversário, fato que provavelmente se remete a que, segundo Garcia (2005), as crianças ditas normais, apesar de aceitarem as deficiências dos colegas, percebem que as mesmas impõem dificuldades ao relacionamento e afetam as amizades, devido às evidentes limitações sofridas pelos deficientes.

As escolhas feitas pelas crianças sem deficiências na entrevista sociométrica, deste estudo, mostraram-se também coerentes com a pesquisa desenvolvida por Batista e Enumo (2004) com três alunos com deficiência mental e seus colegas de classe de ensino regular. A pesquisa identificou que alunos com deficiência são aceitos com menos frequência e mais rejeitados do que seus colegas sem deficiências.

As crianças com deficiências mantêm relações de amizade, apesar das dificuldades geradas por sua própria condição (GARCIA, 2005), 
portanto, é fundamental que se considere a interação entre crianças com e sem deficiência como uma das possibilidades relacionais que servem de contexto para o desenvolvimento de amizades, como um espaço de trocas, que por sua vez, oportuniza os relacionamentos informais entre alunos da educação inclusiva.

Do ponto de vista da socialização e da vida escolar, as amizades vêm revelando um papel central na inserção, no ajustamento e no desempenho escolar, bem como no desenvolvimento de competências sociais e cognitivas, como a partilha, cooperação, lealdade, apoio emocional, comportamento responsável e resolução de conflitos (VILLA; THOUSAND, 1999; BURK; LAURSEN, 2005; RICHARD; SCHNEIDER, 2005; GARCIA, 2006).

$\mathrm{O}$ desejo de eliminar as diferenças é muito claro na legislação. Cabe à sociedade, professores e outros profissionais da educação a tarefa de buscar meios efetivos para aprender a lidar com os alunos com deficiências, a fim de incluir a todos, que mesmo com suas diferenças, possuem habilidades para ajudar na construção de uma sociedade igualitária, onde não haja espaço para exclusão e discriminação (BATISTA; ENUMO, 2004; MANTOAN, 2004).

Uma limitação presente na pesquisa foi a escolha de uma aluna com deficiência visual, sem comprometimento cognitivo, o que não permite que sejam feitas generalizações destes resultados e nem que se façam comparações com outras deficiências. Seria interessante que houvesse mais pesquisas sobre os efeitos diferenciados de cada tipo de deficiência sobre as relações de amizade nas escolas inclusivas.

Os dados coletados sugerem possibilidades para se fomentar novas investigações sobre as interações entre alunos com e sem deficiências que frequentam escolas de ensino regular, a fim de analisar se as interações entre os mesmos se configuram em relações de amizade. Ou ainda, sobre a importância do papel do Professor como mediador das interações que permitirão o desenvolvimento de relações de amizade entre os alunos da educação inclusiva.

\section{Referências}

BATISTA, M. W.; ENUMO, S. R. F. Inclusão escolar e deficiência mental: Análise da interação social entre companheiros. Estudos de Psicologia, Natal, v. 9, n. 1, p. 101-111, jan./abr. 2004.

BEYER, H. O. O projeto da Educação Inclusiva: Perspectivas e princípios de implementação. In: JESUS, D. M. de; BAPTISTA, C. R.; BARRETO, M. A. S. C.; VICTOR, S. L. (Orgs.)., I nclusão, Práticas Pedagógicas e Trajetórias de Pesquisa. Porto Alegre: Mediação/Prefeitura municipal de Vitória/CDV/FACITEC, 2007, p. 7581. 
BISHOP, K. D.; JUBALA, K. A.; STAINBACK, S.; STAINBACK, W. Promovendo Amizades. In: STAINBACK, S.; STAINBACK, W. Inclusão: um guia para educadores. Trad. Magda França Lopes. Porto Alegre: Artes Médicas Sul, 1999, p. 184-199.

BOGDAN, R.; BIKLEN, S. I nvestigação Qualitativa em Educação. Uma introdução à teoria e aos métodos. Porto Editora, 1994, p. 4797.

BRONFENBRENNER, U. A ecologia do desenvolvimento humano: Experiências naturais e planejadas. Tradução, Maria Adriana Verosese. Porto Alegre: Artes Médicas, 1996.

. Environments in developmental perspective: Theoretical and operational models. In: FRIEDMANN, B. L.; WACHS, T. D. (Orgs.). Conceptualization and assessment of environment across the lifespan. Washington, DC: American Psychologial Association, 1999, p. 3-33.

BURK, W. J.; LAURSEN, B. Adolescent perceptions of friendship and their associations with individual adjustment. I nternational J ournal of Behavioral Development, London, v. 29, n. 2, p.156-164, Mar. 2005.

CARVALHO, R. E. Escola Inclusiva: a reorganização do trabalho pedagógico. Porto Alegre: Mediação, 2008, p. 91-100.

CECCONELLO, A. M.; KOLLER, S. H. Inserção ecológica na comunidade: uma proposta metodológica para o estudo de famílias em situação de risco. Psicologia Reflexão e Crítica, Porto Alegre, v.16, n. 3, p. 515-524, 2003.

CORSARO, W. A. Friendship and Peer Culture in the Early Years. EUA: Ablex Publishing Corporation Development. Ethos, 1985.

DANIELS-BEIRNESS, T. Measuring peer status in boys and girls: A problem of apples and of ranges. In: SCHNEIDER, B. H.; ATTILI, G.; NADEL, J.; WEISSBERG, R. P. (Orgs.). Social competence in development perspective. Boston: Kluwer Academic Publishers, 1989.

DORZIAT, A. A inclusão escolar de surdos: um olhar sobre o currículo. In: DE JESUS, D. M.; BAPTISTA, C. R.; BARRETO, M. A. S. C.; VICTOR, S. L. (Orgs.). Inclusão, Práticas Pedagógicas e Trajetórias de Pesquisa. Porto Alegre: Mediação/Prefeitura municipal de Vitória/CDV/FACITEC, 2007, p. 54-62.

FÁVERO, E. A. G.; PANTOJ A, L. M.; MANTOAN, M. T. E. O acesso de alunos com deficiências às escolas e classes comuns da rede regular. Ed. Ver. E atual. Brasília: Procuradoria Federal dos Direitos do Cidadão, 2004.

FERREIRA, M. E. C.; GUIMARÃES, M. Educação Inclusiva. Rio de Janeiro: DP\&A, 2003, p. 107-120.

GARCIA, A. Psicologia da amizade na infância: uma revisão crítica da literatura recente. Interação em Psicologia, 2005, p.287-289. 
Aspectos psicológicos da amizade na infância. In: BANDEIRA, M.; DEL PRETTE, Z. A. P.; DEL PRETTE, A. (Orgs.). Estudos sobre habilidades sociais e relacionamento interpessoal. 1 ed. São Paulo: Casa do Psicólogo, 2006, p. 105-123. GRAHAM, J. A.; COHEN, R.; ZBIKOWSKI, S. M.; SECRIST, M. E. A longitudinal investigation of race and sex as factors in children`s classroom friendship choices. Child Study Journal, Buffalo/NY, v. 28, n. 4, p. 245-266, 1998.

HARRIS, J. R. Where is the child's environment? A group socialization theory of development. Psychological Review, 1995, p. 458-489.

HINDE, R. A. Relationships: A Dialectical Perspective. Hove: Psychology Press, 1997.

KREBS, R. J. A teoria Bioecológica do desenvolvimento humano e o contexto da educação inclusiva. I nclusão - Revista de Educação Especial, Brasília, v. 2, n. 2, p. 44, Ago/2006.

MACHADO, R. Educação Especial na Escola Inclusiva: políticas, paradigmas e práticas. 1 ed., São Paulo: Cortez, 2009.

MANTOAN, M. T. E. Uma escola de todos, para todos e com todos: O mote da Inclusão. In: STOBÄUS, C. D.; MOSQUERA, J. J. M. (Orgs.). Educação Especial: em direção à Educação Inclusiva. 2 ed. Porto Alegre: EDI PUCS, 2004.

MITTLER, P. Educação Inclusiva: contextos sociais. Trad. Windyz Brazão Ferreira. Porto Alegre: Artmed, 2003, p. 23-37.

MORENO, J. L. Fundamentos de la sociometría. Buenos Aires: Paidós, 1962.

OLIVEIRA, I. A. Política de Educação Inclusiva nas Escolas: trajetória de conflitos. In: DE JESUS, D. M.; BAPTISTA, C. R.; BARRETO, M. A. S. C.; VICTOR, S. L. (Orgs.). Inclusão, Práticas Pedagógicas e Trajetórias de Pesquisa. Porto Alegre: Mediação/Prefeitura municipal de Vitória/CDV/FACITEC, 2007, p. 32-40.

RICHARD, J. F.; SCHNEIDER, B. H. Assessing friendship motivation during preadolescence and early adolescence. Journal of Early Adolescence, New York, v. 25, n. 3, p. 367-385, Aug. 2005.

STAINBACK, S.; STAINBACK, W. Inclusão: um guia para educadores. Tradução de Magda França Lopes. Porto Alegre: Artes Médicas Sul, 1999.

STRULLY, J. L.; STRULLY, C. F. As amizades como um objetivo educacional: $O$ que aprendemos e para onde caminhamos. In: STAINBACK, S.; STAINBACK, W. Inclusão: Um guia para educadores. Trad. Magda França Lopes. Porto Alegre: Artes Médicas Sul, 1999, p. 169-183.

TRIVIÑOS, A. N. S. Introdução à pesquisa em Ciências Sociais: a pesquisa qualitativa em educação. São Paulo: Atlas, 1987.

VILLA, R. A.; THOUSAND, J. S. Colaboração dos alunos: Um elemento essencial para a elaboração de currículos no século XXI. In: 
STAINBACK, S.; STAINBACK, W. Inclusão: Um guia para educadores. Trad. Magda França Lopes. Porto Alegre: Artes Médicas Sul, 1999, p. 200-222.

YIN, R. K. Estudo de caso: planejamento e métodos. Trad. Daniel Grassi. 3 ed. Porto Alegre: Bookman, 2005.

\section{Endereço para correspondência}

\section{Rosana Assef Faciola}

Trav. São Francisco, 350, apt. 1003, Batista Campos, CEP 66023-530, Belém - PA, Brasil

Endereço eletrônico: rosanassef@ig.com.br

Fernando Augusto Ramos Pontes

Rodovia dos Trabalhadores, Condomínio Água Cristal, Rua Bejupirá, 39, CEP 66635894, Parque Verde, Belém - PA, Brasil

Endereço eletrônico: fernando.pontes@pq.cnpq.br

\section{Simone Souza da Costa Silva}

Rodovia dos Trabalhadores, Condomínio Água Cristal, Rua Bejupirá, 39, CEP 66635894, Parque Verde, Belém - PA, Brasil

Endereço eletrônico: symon@ufpa.br

Recebido em: 14/06/2010

Reformulado em: 13/09/2010

Aceito para publicação em: 18/10/2010

Acompanhamento do processo editorial: Eleonôra Prestrelo

\section{Notas}

*Doutora em Teoria e Pesquisa do Comportamento (Universidade Federal do Pará (UFPA).

**Doutor em Psicologia Experimental (USP), professor da Universidade Federal do Pará e pesquisador bolsista do CNPq.

$* * *$ Doutora em Psicologia (UNB). 